Relations industrielles

Industrial Relations

\title{
La conduite des réunions, la formation permanente en sciences humaines sous la direction de Roger Mucchielli, Librairies techniques/Entreprise Moderne d'Édition, Paris, avril 1967, 130 pages.
}

\section{Pierre Dionne}

Volume 22, numéro 4, 1967

URI : https://id.erudit.org/iderudit/027845ar

DOI : https://doi.org/10.7202/027845ar

Aller au sommaire du numéro

Éditeur(s)

Département des relations industrielles de l'Université Laval

ISSN

0034-379X (imprimé)

1703-8138 (numérique)

Découvrir la revue

Citer ce compte rendu

Dionne, P. (1967). Compte rendu de [La conduite des réunions, la formation permanente en sciences humaines sous la direction de Roger Mucchielli, Librairies techniques/Entreprise Moderne d'Édition, Paris, avril 1967, 130 pages.] Relations industrielles / Industrial Relations, 22(4), 583-583.

https://doi.org/10.7202/027845ar

Tous droits réservés (C) Département des relations industrielles de l'Université Laval, 1967
Ce document est protégé par la loi sur le droit d'auteur. L'utilisation des services d'Érudit (y compris la reproduction) est assujettie à sa politique d'utilisation que vous pouvez consulter en ligne.

https://apropos.erudit.org/fr/usagers/politique-dutilisation/ 
trielles dans différentes régions comparables au Chili.

Le haut niveau acodémique de cette publication ne fait aucun doute. L'auteur est un professeur de I'Université Cornell où il donne, depuis 1963, un cours sur \& Les Relations Industrielles en Amérique Latine $\gg$. Depuis 1958, il eut très souvent l'occasion de visiter le Chili et d'y travailler, soit comme invité, soit comme membre d'un projet conjoint d'études entre I'Université du Chili (Santiago) et I'Université Cornell. Le volume $a$, de plus, été soumis aux commentaires de nombreux intellectuels, pour la plupart spécialistes du système de relations industrielles de l'Amérique Latine, et a été corrigé collectivement

L'effort de compréhension des Etats-Unis envers l'Amérique Latine est généralement considéré comme insuffisant. Cette publication fait vraisemblablement exception. Elle reflète la qualité et mérite certainement d'être lue.

André PETIT

La conduite des réunions, la formation permanente en sciences humaines sous la direction de Roger Mucchielli, Librairies techniques / Entreprise Moderne d'Edition, Paris, avril 1967, 130 pages.

Cet ouvrage est divisé en deux parties: l'une, intitulée a connaisance du problème $*$, est une partie d'information théorique et de connaissances intellectuelles indispensables sur le thème proposé. L'autre, intitulée " exercices pratiques $»$, est une partie de formation personnelle concrète, présentée de manière progressive.

A la fin de la première partie se trouve un lexique des mots techniques utilisés. A la fin de la seconde, se trouvent des types de programmes pour sessions de perfectionnement de groupe.

La première partie est de beaucoup la plus intéressante et captivante. Le titre des cinq exposés parlent d'eux-mêmes: "Les problèmes psychologiques posés par la conduite des réunions et par la participation , «Parler à un public " Animer un grand groupe », "Le brainstorming », "La conduite des réunions de petit groupe . Chacun de ces exposés suggère des méthodes pour contourner les difficultés inhérentes à ces sujets et en arriver ainsi dे une plus grande efficacité

C'est au centre du livre que le lecteur intéressé par une formation personnelle, trou- vera l'ordonnancement rationnel de cette formation, mettant en oeuvre, parallèlement, les travaux pratiques et l'information. II y verra l'organisation pédagogique de son auto-formation.

Toutefois, cet ouvroge est surtout destiné à tous ceux qui ont ou qui auront o animer une réunion.

\section{Pierre DIONNE}

Le service social dans l'entreprise, par Madeleine Bernard, Editions du Centurion, Socioguides, Paris, 1966, 204 pages.

L'évolution moderne tend à donner, à l'intérieur des entreprises, une place de plus en plus large aux disciplines humaines. Les cadres de l'entreprise, pour faire foce aux situations nouvelles, présentent des qualifications académiques de plus en plus diversifiées. Des gens de profession qu'on considérait autrefois comme exclus de l'entreprise, y trouvent de plus en plus leur place. II semble que ce soit le cas, du moins en France, pour les gens du Service Sociol.

L'auteur, qui a eu elle-même une expérience dans l'entreprise veut aider à définir et à faire connaître cette dimension nouvelle de la profession. Elle nous renseigne donc d'abord sur les différentes responsabilités que peuvent assumer, à l'intérieur de l'entreprise, les gens de sa profession, tout en insistant sur le caractère essentiel d'évolution et de transformation de cette tâche dans un univers technique et social en voie de profond changement. Une vue lucide de la société, telle qu'elle existe, l'amène d̀ traiter des conditions d'insertion de I'assistante sociale dans l'entreprise.

Le service social, qu'on avait tendance à considérer autrefois comme une * vocation * et qu'il faut de plus en plus considérer comme un métier ou une profession est en droit, au même titre que les autres professions de s'interroger sur so propre évolution. Cette discipline est encore jeune, puisqu'il semble que ce travail soit le premier à tenter de faire l'analyse d'une tâche spécialisée de service social. Cette nouvelle dimension professionnelle, Mlle Bernard en donne les conditions d'existence et de développement. Elle termine d'ailleurs par une extrapolation sur le service social d'entreprise dans le monde.

$\mathrm{Ce}$ volume présente donc un intérêt évident pour les gens de service social. II présente aussi de l'intérêt pour n'importe quel 